\title{
Pulmonary Venous Varix: A Typical Diagnosis in Imaging
}

\author{
F. Jaafari ${ }^{1 *}$, B. Bannar ${ }^{1}$, B. Boutakioute ${ }^{1}$, M. Ouali Idrissi ${ }^{1}$, N. Cherif Idrissi Ganouni ${ }^{1}$
}

${ }^{1}$ Radiology Department, ARRAZI Hospital, CHU Mohammed VI, Cadi Ayad University, Marrakech, Morocco

DOI: $10.36347 /$ simcr.2021.v09i03.019

| Received: 28.02.2021 | Accepted: 15.03.2021 | Published: 17.03.2021

*Corresponding author: Fadwa Jaafari

\section{Abstract}

Pulmonary venous varix is a rare focal involvement of a pulmonary vein that becomes dilated. Pulmonary varices are congenital or acquired following distal venous occlusion by a pathology affecting the mitral valve or hepatic cirrhosis. On the chest x-ray, pulmonary varicose veins may be unnoticed or present as a solitary lung nodule next to the left atrium.On chest computed tomography, they take on the appearance of serpeginous vascular structures with no nidus image and no connection with arterial structures frequently found in AVM. Pulmonary varices are asymptomatic with a stable course, requiring no treatment except complications.

Keywords: Thoracic imaging, rare lung disease, vascular anomaly, pulmonary varix, pulmonary venous anomaly, pulmonary venous aneurysm.

Copyright $\odot 2021$ The Author(s): This is an open-access article distributed under the terms of the Creative Commons Attribution 4.0 International License (CC BY-NC 4.0) which permits unrestricted use, distribution, and reproduction in any medium for non-commercial use provided the original author and source are credited.

\section{INTRODUCTION}

Pulmonary venous varix are manifested by focal aneurysmal dilation of a pulmonary vein. There is no predilection for age or gender, and can occur singly or as a result of downstream venous obstruction [1].

Imaging plays an important role in the diagnosis of this pathology and allows them to be distinguished from arteriovenous malformations, as these are two pathologies whose treatment is different [2].

\section{CASE REPORT}

We present the case of a 52-years-old female patient with history of hiatal hernia surgery five days ago; who presented a chest pain with dyspnea during minimal exertion (New York Heart Association class IV). On physical examination her heart rate was 90 bpm, blood pressure was $100 / 60 \mathrm{mmHg}$ and a respiratory rate of 22 breaths/minute and she had normal pulses in all four limbs, precordial thrust in the lower left sternal border and a loud second heart sound without murmurs. Pulmonary examination findings are signs of volume gain, reduced tactile vocal fremitus, dullness on percussion, shifting dullness, and diminished or absent breath sound, and there was no edema, ascites or hepatic splenomegaly.

Acute pulmonary embolism was suspected in Intermediate probability in The Wells and the revised
Geneva score with a high level of D-dimer $>20 \mu \mathrm{g} / \mathrm{ml}$ (reference, 0.001-0.50 $\mu \mathrm{g} / \mathrm{ml}$ ).

However a chest angio-CT scan shows low abundance of pleural and scissural effusion on the left and moderate abundance on the right with atelectasis of the left lower lobe (Figure-1), pulmonary consolidation with aeric bronchogram scattered at the apex and lingula (Figure-2). Individualisation at the ventral segment of the culmen a tortuous dilatation of an intrapulmonary vein flowing into the left superior pulmonary vein (Figure 3 and 4).

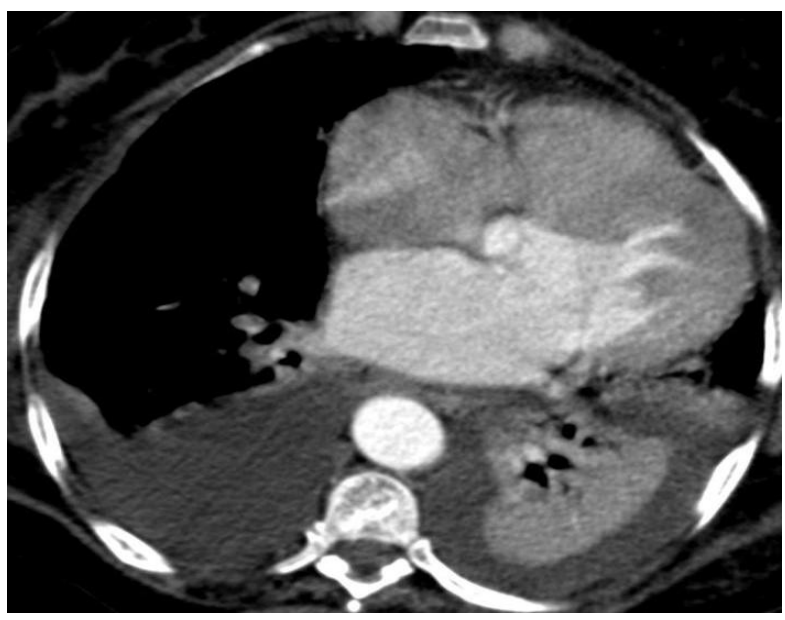

Fig-1: Chest CT axial slice mediastinal window: abundance of pleural and scissural effusion on the left and moderate abundance on the right with atelectasis of the left lower lobe 


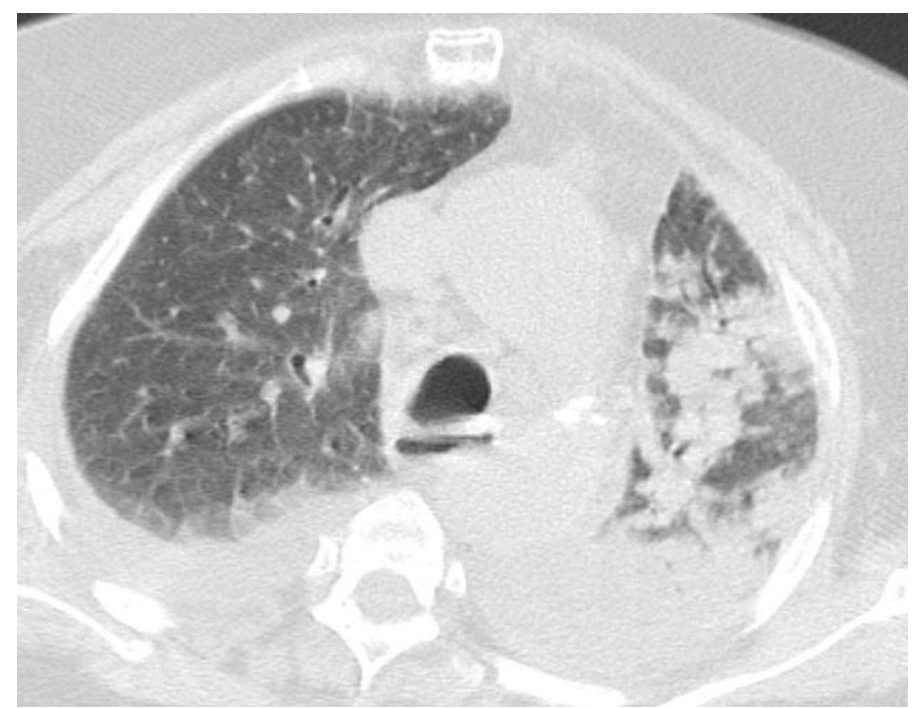

Fig-2: Chest CT axial slice window parenchymal window: consolidation with aeric bronchogam scattered at left apex and lingula
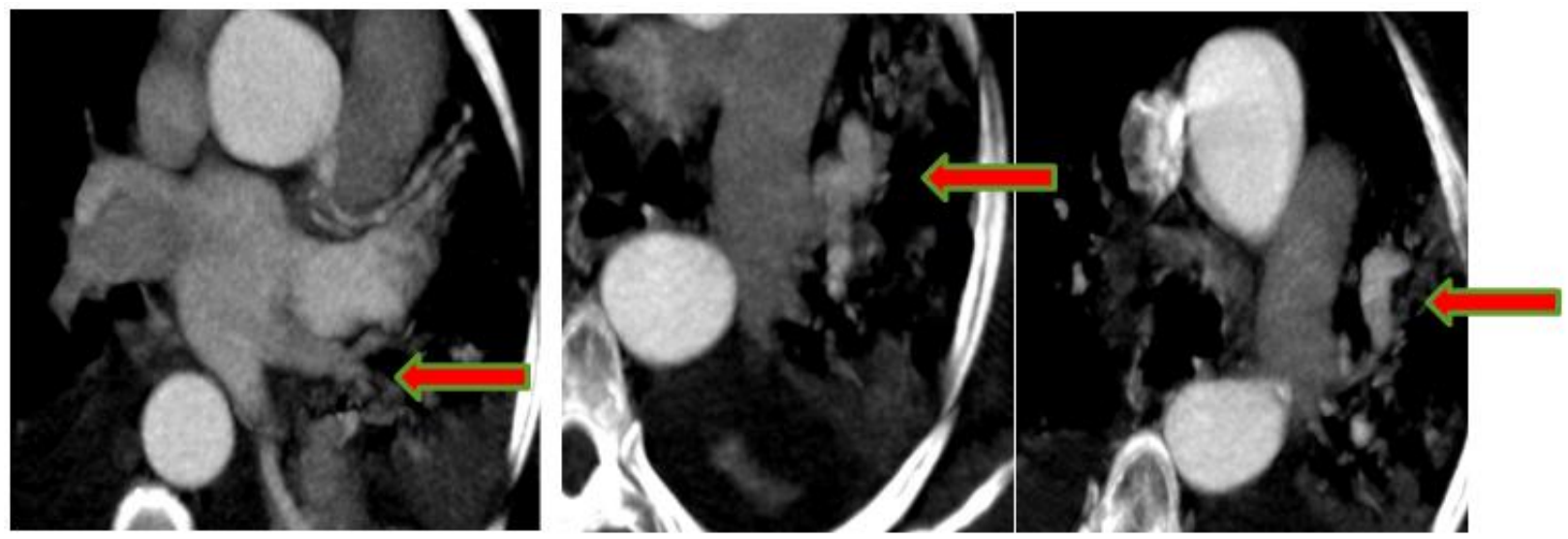

Fig-3: Thoracic angioscanner axial slices mediastinal window: tortuous dilatation of an intra pulmonary vein at the ventral segment of the culmen, flowing into the left superior pulmonary vein

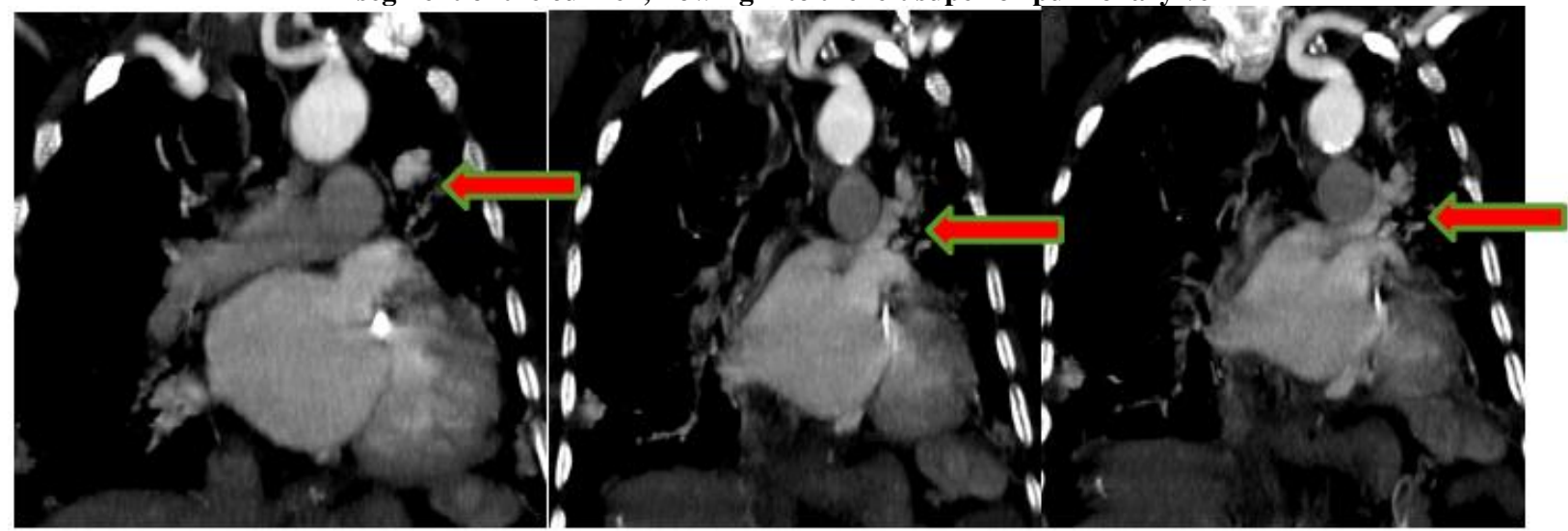

Fig-4: Thoracic angioscan with frontal reconstructions and mediastinal window: tortuous dilatation of an intra pulmonary vein at the ventral segment of the culmen, flowing into the left superior pulmonary vein

\section{DiscUSSION}

Pulmonary venous varix were first described by Puchet in 1843 during the autopsy of a child who died from digestive hemorrhage and presented with multiple multisystemic varices [3]. The second case described was in 1907 by Hedinger-Basel in a postmortem analysis. The first case of pulmonary venous varix diagnosed by angiography in a living patient was in 1951 by Mouquin et al., [4] Pulmonary venous varix is characterized by aneurysmal focal dilation of the pulmonary vein [5]. It is most often asymptomatic and can occur singly or as a result of downstream venous obstruction $[6,7]$. There is no predilection for age or gender [5]. It is a rare disease with an unknown incidence [8].Pulmonary varices are seen on the chest 
$\mathrm{X}$-ray as oblong or round pulmonary or paramediastinal opacities.Uyama et al., [9] proposed a classification with 3 subtypes of pulmonary varices on chest $\mathrm{x}$-ray based on a review of 67 cases. Type 1: saccular: localized saccular dilation of the pulmonary vein. Type 2: tortuous: elongated and tortuous dilation of the pulmonary vein. Type 3: confluent dilation: dilation of the confluence of the pulmonary veins.

The appearance of Pulmonary venous varix on chest radiography remains non-specific since it does not allow proof of the relationship between visualized opacity and the pulmonary vein, but it remains a firstline imaging means and screening tool, its usefulness for surveillance has not yet been demonstrated.

The thoracic CT angiography image is in the form of a tortuous vascular structure of increased caliber compared to a pulmonary vein and empties into the left atrium, the disadvantage is that the CT angiography is sensitive to flow artefacts and thus the filling of blood Pulmonary veins can be simultaneous with the arteries witch limited the correct analysis [11].

Although high-resolution thoracic CT angiography is a modality of choice in terms of Pulmonary venous varix, other imaging modalities capable of identifying the flow remain useful such as phase contrast magnetic resonance imaging (MRI) which provides information on changes in blood flow in the thoracic and pulmonary vascular system [12]. It also makes it possible to visualize the pulmonary varicose vein as a serpeginous vascular structure draining from the atrium with the advantage that it is less irradiating and without recourse to iodinated contrast product.

The angio-MRI can confirm the simultaneous opacification of the pulmonary venous varix with the pulmonary veins with a re-graded emptying time. [12]In addition, it makes it possible to differentiate an arteriovenous malformation from a Pulmonary venous varix by cine MRI encoded in speed of the aorta and of the main pulmonary artery which will not show any sign of shunt (Qp / Qs = 1) [13].

The reference examination remains selective pulmonary angiography by catheter. The arterial architecture is normal in the arterial phase in cases of Pulmonary venous varix, unlike pulmonary arteriovenous malformations. During the venous phase, varicose veins will flow into the common pulmonary vein and then into the left atrium.

Bartram and Strickland and Berecova et al, used specific procedures to diagnose pulmonary venous varix on angiography [14] which are as follows: (1) normal pulmonary arteries; (2) no evidence of pulmonary arteriovenous fistula; (3) simultaneous deposition of varicose veins and normal pulmonary veins; (4) varicose veins draining into the left atrium;
(5) prolonged emptying of varicose veins compared to normal veins; and (6) dilated and tortuous varicose veins are central, near the hilum, with normal peripheral veins.

Although the role of ETO in the diagnosis of pulmonary venous varix is limited to case reports, some authors have suggested that it is useful for the diagnosis of this pathology without resorting to pulmonary catheter angiography $[15,16]$. On the other hand it has another advantage, such as the evaluation of the mitral valve which can be suggested to anomalies often associated with acquired pulmonary venous varix [10].

Pulmonary venous varix can induce esophageal compression with dysphagia or bronchial compression leading to middle lobe syndrome or hemptysis by rupture, rarely cerebral infarction [17-19].

Treatment is not necessary for asymptomatic pulmonary venous varix, but monitoring is imperative to detect complications or an increase in size requiring surgery $[19,20]$.

For patients with mitral valve disease with pulmonary venous hypertension, it is necessary to undergo valve replacement surgery especially if the pulmonary venous varix increases in size [21].

\section{CONCLUSION}

Pulmonary vein varices is a rare entity, often asymptomatic with fortuitous discovery, the diagnosis is radiological with a thoracic CT angiography or ideally by selective pulmonary angiography by catheter. Treatment is not indicated in the asymptomatic form, it is often directed to the underlying cause and not the varix itself.

\section{REFERENCES}

1. Haddad J, Badran A, Pavão R, de Padua AI, Lago I, Marin Neto JA. Pulmonary varix: A case report. Revista Portuguesa de Cardiologia. 2016;35(7-8), 443.e1-443.e4.

2. Gleason JB, Shekar SP, Hernandez F, Valentin R, Mehta JP. Pulmonary Varix. Clinical Pulmonary Medicine, 2017; 24(2), 87-91.

3. Arnett JC, Patton RM. Pulmonary varix. Thorax. 1976;31: 107-112.

4. Bartram C, Strickland B. Pulmonary varices. Br J Radiol. 1971; 44:927-935.

5. Kumazow H, Komori M, Ochiai R, Egashira R, Nakazono T, Kudo S. Pulmonary varix mimicking arteriovenous malformation. Clin Imaging. 2008;32:61-64.

6. Vanherreweghe E, Rigauts H, Bogaerts Y, Meeus L. Pulmonary vein varix: diagnosis with multislice helical CT. Eur Radiol. 2000;10:1315-1317. 
F. Jaafari et al., Sch J Med Case Rep, Mar, 2021; 9(3): 265-268

7. Kelser G, Adkins P, Shefferman M. Pulmonary varix regression after mitral valve replacement. Am J Cardiol. 1976;37:928-932.

8. Emmert A, Jebran A, Schmidt K, Hinterthaner M, Bohnenberger H, Bahr M. Aneurysm of the pulmonary vein: an unusual cause of stroke. Ann Thorac Surg. 2014;98(5):1841-1843.

9. Uyama T, Monden Y, Harada K, Tamaki H, Miura K, Taniki T, Kimura S, Hashioka K, Nobuhara K. Pulmonary varices: a case report and review of the literature. The Japanese journal of surgery. 1988 May;18(3):359-62.

10. Shida T, Ohashi H, Nakamura K, Morimoto M. Pulmonary varices associated with mitral valve disease: a case report and survey of the literature. The Annals of thoracic surgery. 1982 Oct 1;34(4):452-6.

11. Abujudeh H. Pulmonary varix: blood flow is essential in the diagnosis. Pediatr Radiol. 2004;34:567.

12. Wiebe S, Maclusky I, Manson D, Holowka S, Yoo SJ. Hemoptysis: a rare cause can be related to a bronchial varix due to pulmonary venous obstruction. Pediatric radiology. 2003 Dec;33(12):884-6.

13. Wildenheim P, Bourekas E. Pulmonary varix: magnetic resonance findings. Cathet Cardiovasc Diagn. 1991;24:268-270.

14. Berecova Z, Neuschl V, Boruta P, Masura J, Ghersin E. A complex pulmonary vein varix- diagnosis with ECG gated MDCT, MRI and invasive pulmonary angiography. Journal of radiology case reports. 2012 Dec;6(12):9.

15. Toher C, Krug H, Archer SL. Diagnosis of pulmonary vein varix by transesophageal echocardiography. Chest. 1993;103: 1901-1903.

16. Shiraishi J, Tatsumi T, Kimata M, Kambayashi D, Mano A, Yamanaka S, Kobara M, Azuma A, Nakagawa M. Echocardiographic diagnosis of pulmonary vein varix. Circulation journal. 2003;67(9):796-8.

17. Haddad J, Badran A, Pavao R, De Padua A, Lago I, Marin Neto J. Pulmonary varix: a case report. Rev Port Cardiol. 2016;35(7-8):443.

18. Berecova Z, Neuschi V, Boruta P, Masura J, Ghersin E. A pulmonary vein varix-diagnosis with ECG gated MDCT, MRI and invasive pulmonary angiography. J Radiol Case Rep. 2012;6(12):9-16.

19. Tajiri S, Koizumi J, Hara T, Kamono M, Hayama N, Kobayashi I. A case of pulmonary varix associated with superior pulmonary vein occlusion. Ann Vasc Dis. 2012;5(3):381-384.

20. Emmert A, Jebran A, Schmidt K, Hinterthaner M, Bohnenberger $\mathrm{H}$, Bahr $\mathrm{M}$. Aneurysm of the pulmonary vein: an unusual cause of stroke. Ann Thorac Surg. 2014;98(5):1841-1843.

21. Kelser G, Adkins P, Shefferman M. Pulmonary varix regression after mitral valve replacement. Am J Cardiol. 1976;37:928-932. 